\title{
Effect of intravenous diazepam on human lower oesophageal sphincter pressure under controlled double blind crossover conditions
}

\author{
T. R. WEIHRAUCH ${ }^{1}$, CH. F. FÖRSTER, H. KÖHLER, K. EWE, AND \\ J. KRIEGLSTEIN
}

From the Departments of Medicine and Surgery, University of Mainz, and the Department of Pharmacology and Toxicology, University of Marburg, Federal Republic of Germany

SUMMARY The effect of diazepam on the lower oesophageal sphincter (LOS) pressure is controversial. Therefore, a double-blind crossover study was performed on 18 healthy volunteers to determine the sphincter response to intravenous diazepam $-70,140,280 \mu \mathrm{g} / \mathrm{kg}$, which correspond to a total dose of 5,10 , and $20 \mathrm{mg}$, respectively. After the 5 and $10 \mathrm{mg}$ dose no significant effect on LOS pressure could be observed when compared with placebo. After the $20 \mathrm{mg}$ dose a significant rise in pressures $\left(\Delta \mathrm{P}_{\text {LOS }}\right)$ was recorded for 40 minutes with a maximum $\Delta \mathrm{P}_{\text {LOS }}$ of $+16 \cdot 2 \pm 6.6$ (mean $\pm \mathrm{SEM}$ ) mmHg after 50 minutes $(\mathrm{P}<0.01)(46 \pm 1 \cdot 3 \%$ increase above the basal pressure). It is concluded that diazepam does not affect lower oesophageal sphincter competence and therefore does not increase the risk of regurgitation and pulmonary aspiration in premedicated patients.

The high pressure zone between stomach and oesophagus, the functionally defined lower oesophageal sphincter, is a major determinant in the prevention of gastro-oesophageal reflux (Ingram et al., 1959; Pope, 1967; Winans and Harris, 1967; Cohen and Harris, 1970; Haddad, 1970; Cohen and Harris, 1971; Boesby, 1977; Fisher et al., 1977). Therefore, the effect of drugs which lower the sphincter pressure are of great clinical interest because of the increased risk of gastro-oesophageal reflux. Hall et al. (1975) reported significant reductions in lower oesophageal sphincter pressures and an increased rate of gastrooesophageal reflux in man after intravenous administration of 2.5 to $10 \mathrm{mg}$ diazepam. They concluded that an increased risk of regurgitation and pulmonary aspiration should be taken into account after the administration of diazepam for premedication or postoperative sedation, especially in patients known to experience gastro-oesophageal reflux. As the results of this uncontrolled study by Hall et al. did not agree with the observations of other authors (Siewert and Jennewein, personal communication)

\footnotetext{
${ }^{1}$ Address for correspondence: Dr T. R. Weihrauch, 1. Medizinische Klinik of the University of Mainz, Langenbeckstr. 1, D-65 Mainz, Germany.
}

Received for publication 25 July 1978 and our results based upon a pilot study, the present study was initiated to determine the effect of various doses of diazepam on lower oesophageal sphincter pressure in man in a controlled double-blind crossover study.

\section{Methods}

The original goal of the present study was to evaluate the effect of 70 and $140 \mu \mathrm{g} / \mathrm{kg}$ diazepam intravenously on lower oesophageal sphincter pressure in 12 subjects, a dose range corresponding to that administered by Hall et al. (1975). But, as no significant changes in lower oesophageal spincter pressures could be observed after these doses in a 50 minute period (group I), the study was extended to six further subjects (group II) to investigate the effect of a higher dose $(280 \mu \mathrm{g} / \mathrm{kg})$ for a longer period of time $(120$ minutes). A dose of $140 \mu \mathrm{g} / \mathrm{kg}$ was given as a reference dosage.

\section{SUBJECTS}

Eighteen healthy volunteers were studied in two groups. Group I consisted of 12 subjects, four of whom were females and eight males with a mean age of 23 years (range of 20 to 25 years). Group II consisted of six subjects (three females and three males) with a mean age of 24 years (range of 23 to 26 
years). Informed consent was obtained from each volunteer.

INTRALUMINAL PRESSURE MEASUREMENT Oesophageal manometry was performed with the intraluminal transducer system (Förster-Enteromat M 5000) which has been described previously (Förster et al., 1976, 1977; Weihrauch and Förster, 1977). For this newly developed microtransducer (9 $\mathrm{mm}$ in length and $5.8 \mathrm{~mm}$ in diameter) inductance was used for the transformation of intraluminal pressures into electrical signals. The transducer is mounted at the tip of a probe which is passed into the stomach via the mouth. Pressures were recorded on a Metrapid pen recorder. The rapid pull-through technique was applied. The lower oesophageal sphincter was identified by its characteristic pressure profile and by its relaxation on swallowing. Basal values were recorded for 15 minutes before diazepam and placebo, respectively, were administered. Pullthroughs were performed in mid-respiratory position. Sphincter pressures were recorded in $\mathrm{mmHg}$ and expressed as the mean value obtained by five consecutive pull-throughs from the zone of maximal sphincter pressures. Atmospheric pressure was used as zero reference.

\section{PROCEDURE}

All studies were performed in the morning after an overnight fast with the subject in the supine position. Each volunteer was studied on three separate days with 48 hour intervals. After a rest period of 10 minutes five consecutive pull-throughs were performed at 10 minute intervals. Additionally, in group II one pull-through was performed every minute during the first eight minutes to determine a possible immediate sphincter response to diazepam. Subjects of group I received 70 and $140 \mu \mathrm{g} / \mathrm{kg}$ diazepam and a placebo (normal saline), subjects of group II 140 and $280 \mu \mathrm{g} / \mathrm{kg}$ diazepam and placebo at random. The injections were administered over a period of three minutes by a perfusion pump (Unita I, Braun Melsungen, Comp.). Blood pressures and pulse rates were monitored continuously.

\section{INTERPRETATION OF DATA}

All tracings were coded and read blindly after the studies of group I and group II had been completed. Data were expressed as means \pm SEM. Student's $t$ test for paired data was used to test the significance between the means of LOS pressure changes ( $\left.\Delta \mathbf{P}_{\text {LOS }}\right)$ in relation to the basal LOS pressure.

\section{Results}

The basal and post-injection sphincter pressures of group I are shown in Fig. 1 and those of group II in Fig. 2. With the doses of 70 and $140 \mu \mathrm{g} / \mathrm{kg}$ (which correspond to a total dose of 5 and $10 \mathrm{mg}$ ) no significant change in lower oesophageal sphincter pressure $\left(\Delta \mathrm{P}_{\text {LOS }}\right)$ could be observed in the 12 subjects of group I during the 50 minute observation period, compared with placebo. In group II $\Delta \mathbf{P}_{\text {LOS }}$ were also not significant after the application of $140 \mu \mathrm{g} / \mathrm{kg}$. In contrast to that, the sphincter responses to $280 \mu \mathrm{g} / \mathrm{kg}$ (which corresponds to a total dose of $20 \mathrm{mg}$ ) were significant in the time period from 40 to 80 minutes $(\mathrm{P}<0.005$ and $\mathrm{P}<0.025$, respectively), with a maximum $\Delta \mathrm{P}_{\operatorname{LOS}}$ of $+16 \cdot 2 \pm$ $6.6 \mathrm{mmHg}(46 \pm 1.3 \%$ increase above the basal pressure) after 50 minutes $(\mathrm{P}<0 \cdot 01) . \Delta \mathbf{P}_{\text {LOS }}$ after placebo were statistically not significant. After 120 minutes the pressures had returned to the range of the placebo values. Pressure recordings in group II during the first eight minutes showed no significant differences of $\Delta \mathrm{P}_{\mathrm{LOS}}$ between the two dosages and the placebo. No significant changes of intragastric pressure were observed. In no case was a sustained reduction in sphincter pressures observed after the three different diazepam dosages. No significant changes in blood pressures and pulse rates were noted.

\section{Discussion}

Diazepam is one of the most commonly used sedatives. Its property of reducing anxiety and producing a certain degree of amnesia (Goodman and Gilman, 1970) has led to the use of intravenous diazepam for premedication before endoscopic procedures and for sedation before and after surgery. Since gastrooesophageal reflux and pulmonary aspiration may be complications in these procedures, the effect of premedication drugs on the lower oesophageal sphincter, a major determinant of gastro-oesophageal reflux, has increasingly been taken into consideration (Bettarello et al., 1960; Lind et al., 1967; Skinner and Camp, 1968; Pedersen et al., 1971; Hall et al., 1975; Sehhati et al., 1976). According to these studies atropine, morphine sulphate, pethidine hydrochloride, and promethazine reduce and triflupromazine hydrochloride increases lower oesophageal sphincter pressure. The first report on the effect of diazepam on the gastro-oesophageal junction was published by Hall et al. (1975) who observed a reduction in sphincter pressures after the administration of 2.5 to $10 \mathrm{mg}$ diazepam intravenously in an uncontrolled study. These results are in contrast to the results of the present study. As the authors do not indicate when the single post-injection pressures which had been compared with the basal values were read, it is not possible further to evaluate the contra- 


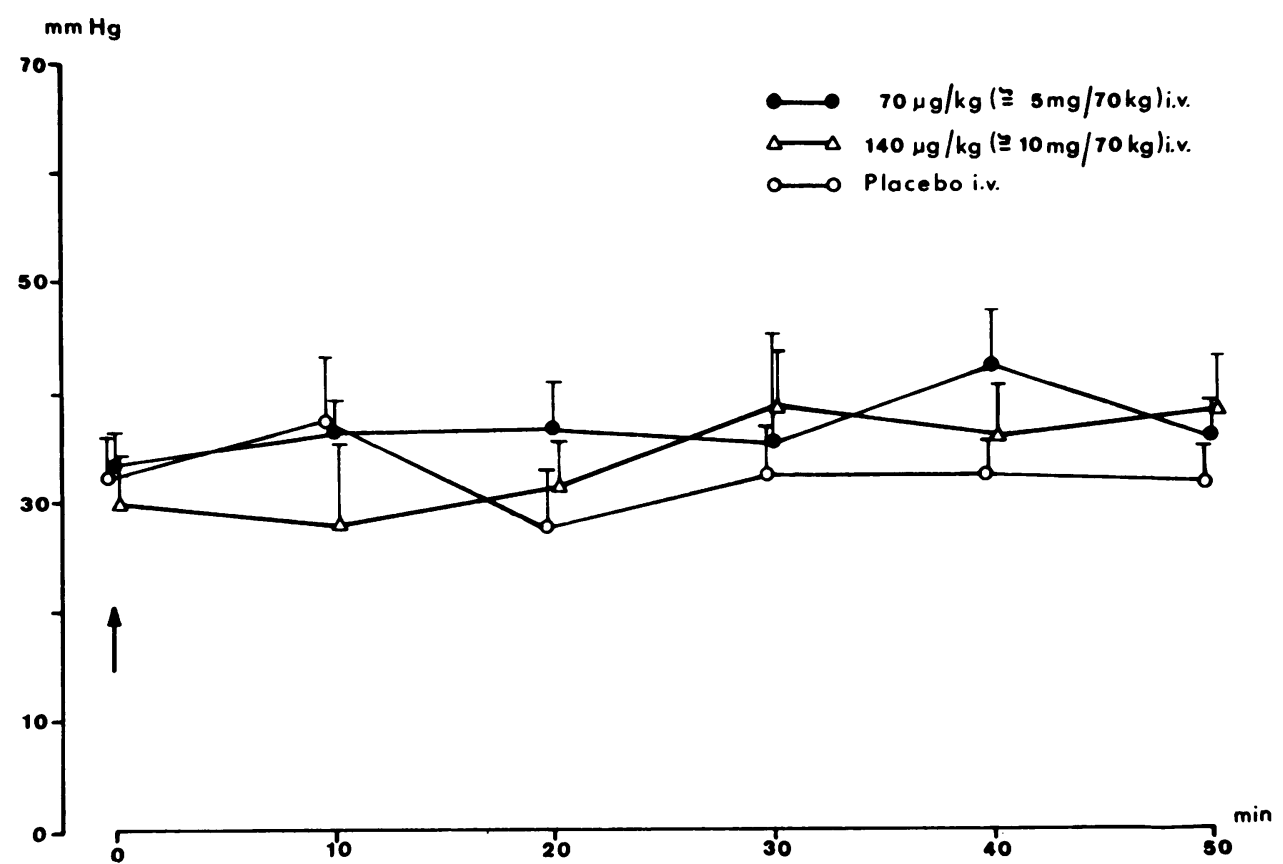

Fig. 1 Effect of 70 and $140 \mu \mathrm{g} / \mathrm{kg}$ diazepam i.v. on the lower oesophageal sphincter pressure in 12 healthy volunteers (group I). Diazepam and placebo were administered to all subjects at random and crossover. None of the differences were significant. Values are given as means $\pm S E M$.

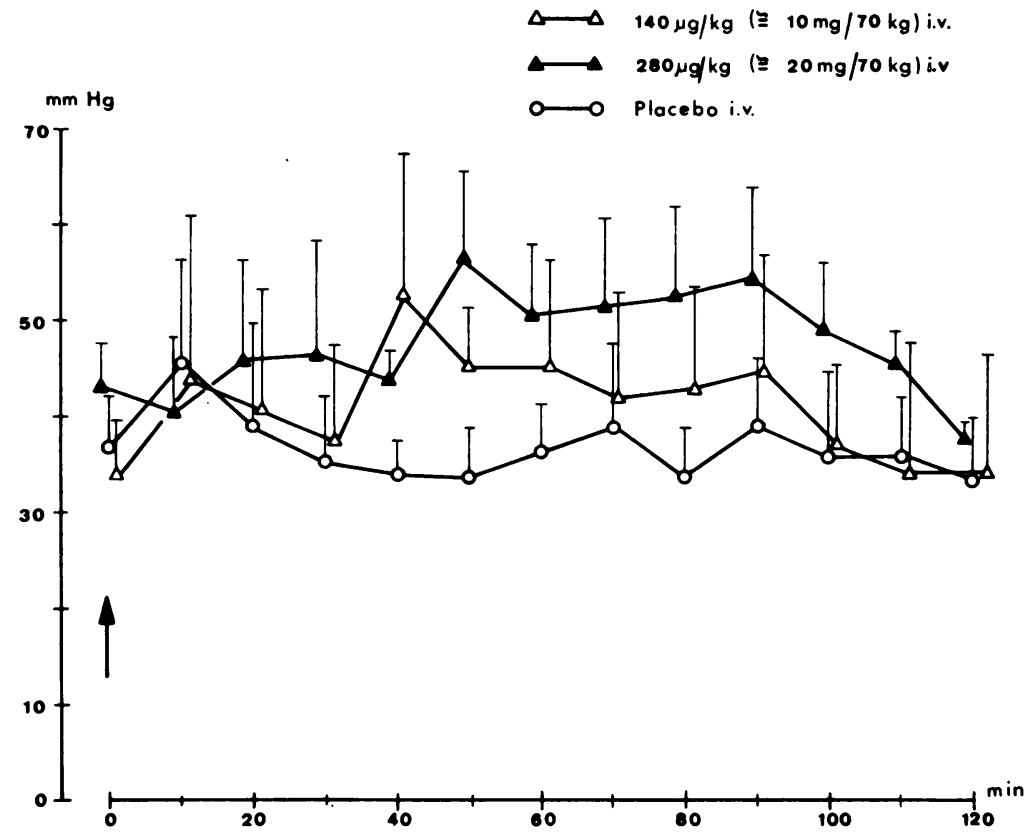

Fig. 2 Effect of 140 and $280 \mu \mathrm{g} / \mathrm{kg}$ diazepam i.v. on lower oesophageal sphincter pressure in six healthy volunteers (group II). The increase in sphincter pressure $\left(\Delta P_{\mathrm{LOS}}\right)$ following the injection of $280 \mu \mathrm{g} / \mathrm{kg}$ was statistically significant after 40 to $80 \mathrm{~min}$, whereas the pressure changes after $140 \mu \mathrm{g} / \mathrm{kg}$ and after placebo were not significant. Values are given as means \pm SEM. 
dictions in their observations and our results. As in our study the dose range applied by Hall et al. (1975) (approximately 5 and $10 \mathrm{mg}$ diazepam in a subject weighing $70 \mathrm{~kg}$ ) did not lower the sphincter pressure but rather increased it, our investigation was extended. In order to assess a possible immediate effect developing within the first few minutes or later than 50 minutes after the injection, which would have been missed in the first study (group I), studies in group II were carried out taking these factors into account. However, this second study also failed to show a decrease in sphincter pressure.

No explanation for this effect of diazepam on the smooth muscle of the distal oesophagus can be given at the present time, as the mode of action of benzodiazepines is unknown.

As diazepam reduces gastric acid secretion (Birnbaum et al., 1971; Bennett et al., 1975; Roberts and Oldrey, 1975) a gastrin-mediated increase in sphincter pressure is unlikely. An $\alpha$-adrenergic stimulation of the sphincter due to a reduction in blood pressure could be excluded by continuous monitoring of this parameter.

The results indicate that, in small doses, diazepam does not influence lower oesophageal sphincter pressures but pressures are increased when higher doses are used. It may, therefore, be concluded that diazepam has no negative effect on lower oesophageal sphincter competence and, for this reason, does not increase the risk of regurgitation and pulmonary aspiration when used for premedication or for postoperative sedation.

\section{References}

Bennett, P. N., Davies, P., Frigo, G. M., Weerasinghe, W. M. T., and Lennard-Jones, J. E. (1975). Effect of diazepam on unstimulated and on stimulated gastric secretion. Scandinavian Journal of Gastroenterology, 10, 101-103.

Bettarello, A., Tuttle, S. G., and Grossman, M. I. (1960). Effect of autonomic drugs on gastrooesophageal reflux. Gastroenterology, 39, 340-346.

Birnbaum, D., Karmeli, F., and Tefera, M. (1971). The effect of diazepam on human gastric secretion. Gut, 12, 616-618.

Boesby, S. (1977). Relationship between gastro-oesophageal acid reflux, basal gastro-oesophageal sphincter pressure, and gastric acid secretion. Scandinavian Journal of Gastroenterology, 12, 547-551.

Cohen, S., and Harris, L. D. (1970). Lower esophageal sphincter pressure an as index of lower esophageal sphincter strength. Gastroenterology, 58, 157-162.

Cohen, S., and Harris, L. D. (1971). Does hiatus hernia affect competence of the gastroesophageal sphincter? New England Journal of Medicine, 284,1053-1056.

Fisher, R. S., Malmud, L. S., Roberts, G. S., and Lobis, I. F. (1977). The lower esophageal sphincter as a barrier to gastroesophageal reflux. Gastroenterology, 72, 19-22.

Förster, C. F., Weihrauch, T. R., Höhle, K. D., and Seitz, W. (1976). Intraluminale Druckmessung mit einen neuen elektronischen Messwertwandler. Verhandlungen der Deutschen Gesellschaft für Innere Medizin, 82, 989-991.

Förster, C. F., Weihrauch, T. R., Brummer, A., Vallerius, P., and Lehmann, H. (1977). A new electronic transducer system for gastrointestinal pressure studies. Medical Progress through Technology, 4, 169-175.

Goodman, L. S., and Gilman, A. (1970). The Pharmacological Basis of Therapeutics. MacMillan: New York.

Haddad, J. K. (1970). Relation of gastroesophageal reflux to yield sphincter pressures. Gastroenterology, 58, 175-184.

Hall, A. W., Moossa, A. R., Clark, J., Cooley, G. R., and Skinner, D. B.(1975). The effects of premedication drugs on the lower oesophageal high pressure zone and reflux status of Rhesus monkeys and man. Gut, 16, 347-352.

Ingram, P. R., Respess, J. C., and Muller, W. H., Jr. (1959). The role of an intrinsic sphincter mechanism in the prevention of reflux esophagitis. Surgery, Gynecology, and Obstetrics, 109, 659-667.

Lind, J. F., Crispin, J. S., and McIver, D. K. (1967). The effect of atropine on the gastroesophageal sphincter. Canadian Journal of Physiology and Pharmacology, 46, 233-238.

Pedersen, S. A., Alstrup Nielsen, P., and Rahbek Sørensen, $H$. (1971). The effect of atropine and hexamethonium in combination on the lower esophageal sphincter. Scandinavian Journal of Gastroenterology, 6, Supplement 9, 43-47.

Pope, C. E. (1967). A dynamic test of sphincter strength: its application to the lower esophageal sphincter. Gastroenterology, 52, 779-786.

Roberts, D. M., and Oldrey, T. B. N. (1975). The effect of diazepam on pentagastrin-stimulated and nocturnal (sleeping) gastric secretion in man. American Journal of Gastroenterology, 63, 396-399.

Sehhati, G., Frey, R., Gerbershagen, H. U., Reicherts, M., and Schulz, H. (1976). Influence of i.v.-narcotics on the lower esophageal sphincter as a regurgitation-barrier. International Congress on Emergency and Critical Care Medicine, Pittsburgh, Pennsylvania.

Skinner, D. B., and Camp, F. F. (1968). Relation of esophageal reflux to lower esophageal sphincter pressures decreased by atropine. Gastroenterology, 54, 543-551.

Weihrauch, T. R., and Förster, Ch. F. (1977). A new transducer system for intraluminal esophageal manometry (Abstract). Gastroenterology, 72, 1147.

Winans, Ch. S., and Harris, L. D. (1967). Quantitation of lower oesophageal sphincter competence. Gastroenterology 52, 773-778. 